\title{
Analyte Specificity
}

National Cancer Institute

\section{Source}

National Cancer Institute. Analyte Specificity. NCI Thesaurus. Code C134032.

The ability to assess unequivocally the analyte in the presence of other components

which may be expected to be present. 